\title{
A PIEDAD DEL MUSEO DE BELLAS ARTES
DE ASTURIAS. LA OBRA Y SUS MODELOS
}

RAQUEL SÁENZ PASCUAL

Universidad de Oviedo

rsaenz@uviovi.es

Resumen: La tabla de La Piedad conservada en el Museo Bellas Artes de Asturias es una obra devocional atribuida al Maestro de las Medias Figuras Femeninas. Para la composición de esta obra, compuesta por varios temas de la Pasión, siguió modelos ya utilizados en otros talleres flamencos, como los de David y Benson, así como un grabado de Durero.

Palabras clave: Pintura flamenca / Maestro de las Medias Figuras Femeninas / Durero / Piedad / Arma Christi / modelos de taller / grabados.

Abstract: The Piety preserved in the Museum of Fine Arts of Asturias is a devotional piece attributed to the Master of the Female Half-Lengths. To create this painting, which depicts several passages of the Passion, the artist followed models that had already been used in other Flemish workshops, as David's and Benson's, as well as in an engraving made by Durer.

Key words: Flemish painting / Master of the Female Half-Lengths / Dürer / Pietà / Arma Christi / Workshop models / engravings.

En el Museo de Bellas Artes de Asturias se conserva una Piedad atribuida al Maestro de las Medias Figuras Femeninas (Fig. 1). Es una pintura sobre tabla $(54.2 \times 41.4 \mathrm{~cm})$ procedente de una colección particular española; fue adquirida por el Museo en 1986. En las siguientes páginas intentaremos realizar el primer estudio monográfico de esta pintura flamenca: analizaremos su estilo y su vinculación con otras obras atribuidas a este maestro, examinaremos el origen de su composición y estableceremos una comparación con modelos tipológicos similares. También se prestará atención a la iconografía que presenta, propia de una obra de carácter devocional. ${ }^{1}$

\section{Una pintura devocional}

Aunque esta pintura aparece titulada como La Piedad, en realidad es una composición compleja formada por varias escenas del ciclo de la Pasión y Resurrección de Cristo. En el centro de la tabla, de mayor tamaño que el resto, aparece la Piedad propiamente dicha: La Virgen se arrodilla junto al cuerpo de su Hijo que descansa sobre un gran lienzo blanco. Sus cuerpos se sitúan en posición paralela. La Virgen se inclina ligeramente hacia Él, sujeta su cabeza por detrás y le mantiene incorporado. En primer plano, sobre el suelo, aparece la corona de espinas. Sobre la Piedad, en el mismo eje central de la composición, un círculo de nubes rodea un espacio luminoso donde aparecen varios ángeles portando las Arma Christi: es una clara alusión a la Pasión de Cristo. Se ha destacado la cruz, no sólo por su localización también en el eje central sino también por sus dimensiones mayores, al igual que las del ángel que la abraza. En un segundo plano, a la izquierda, se representa el Santo Entierro, el momento en que el cuerpo de Cristo es introducido en un sarcófago delante de una cueva. En la parte de la derecha de la tabla se sitúa la Resurrección triunfante de Cristo. ${ }^{2}$

\footnotetext{
* Fecha de recepción: 15 de abril de 2017 / Fecha de aceptación: 12 de julio de 2017.

${ }_{1}$ Agradezco al Museo de Bellas Artes de Asturias, y en especial a su Director Dr. D. Alfonso Palacio, las facilidades ofrecidas para el estudio de esta pintura.

2 En los extremos superiores de la tabla se aprecian modificaciones del soporte, que llevan a plantearse si esta pintura tenía en origen un remate curvo.
} 


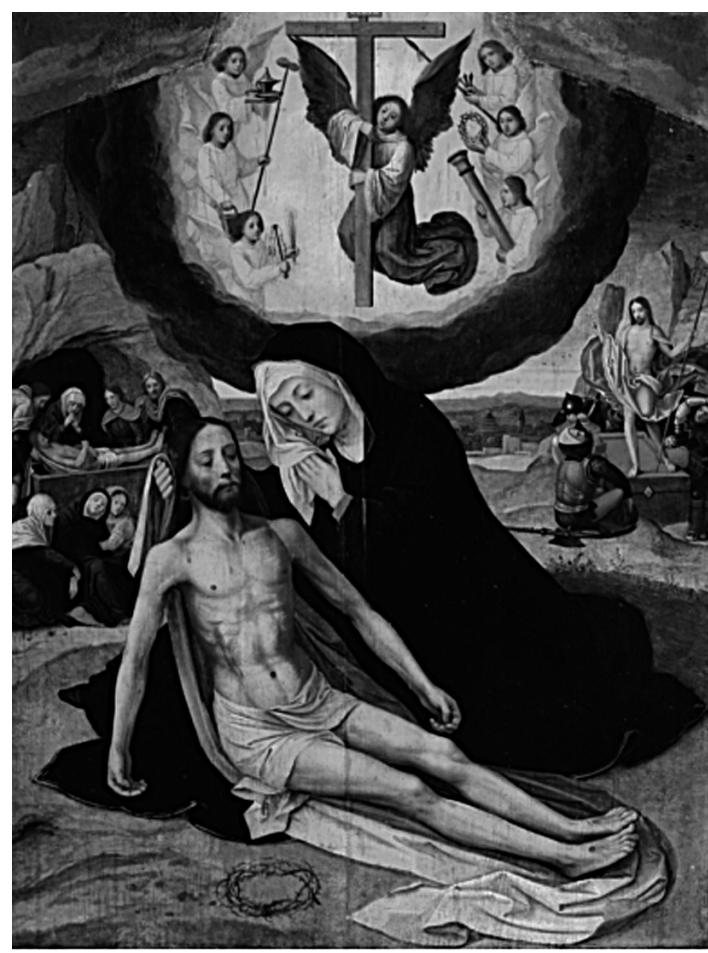

Fig. 1. Maestro de las Medias Figuras Femeninas. La Piedad. Museo de Bellas Artes de Asturias. CMuseo de Bellas Artes de Asturias.

El reducido tamaño de esta pintura y las imágenes representadas permiten calificar esta obra como pintura devocional. En efecto, su tamaño indica que está pensada para ser expuesta en un ambiente íntimo, recogido, de oración y no para ser expuesta ante una gran multitud. Respecto a su iconografía, es evidente que se han seleccionado momentos especialmente duros en lo emocional: la Virgen, una madre, tiene ante Ella el cuerpo inerte de su Hijo, muerto de una manera terrible; la escena del Santo Entierro nos muestra el dolor de los allegados de Cristo. Se busca claramente la empatía del espectador, del fiel. Debemos entender esta obra dentro de la religiosidad del momento, donde tenían gran importancia las devociones privadas y expresada en movimientos como la Devotio Moderna, ya desde el siglo XV.

Esta obra no sólo busca la empatía, también requiere la reflexión del espectador, del fiel. En ese sentido se comprende el desarrollo de la parte superior de la pintura, con la escena de los ángeles portando los Instrumentos de la Pasión. Se pretende que el fiel reflexione sobre el sentido del sufrimiento de Cristo para, de esa manera, alcan- zar un estado de conexión religioso. Esa parte de los ángeles se separa de los hechos que ocurren en la tierra en ese momento gracias a un círculo de nubes espesas. Esa barrera y la luz dorada del espacio donde aparecen los ángeles son una clara alusión a lo celestial, a lo sagrado; trascienden la realidad humana. $Y$ a nuestra derecha se sitúa la Resurrección gloriosa y triunfante de Cristo, el final del sufrimiento. La pintura muestra al fiel el auténtico sentido de la Pasión y muerte de Cristo: vencer al pecado, a la muerte para ofrecerle la Salvación y la Vida Eterna.

\section{Una pintura atribuida al Maestro de las Medias Figuras Femeninas}

La Piedad del Museo de Bellas Artes de Asturias se atribuye al Maestro de las Medias Figuras Femeninas. En el momento de su adquisición por parte de esta institución se contó con un breve informe de la Dra. D ${ }^{a}$ Elisa Bermejo, especialista en pintura flamenca, confirmando esta atribución.

Las obras conocidas que se atribuyen a este maestro muestran entre ellas diferencias estilísticas que hacen pensar en más de una personalidad artística pendiente de definir. No obstante, tras este nombre convencional, aplicado a un elevado número de pinturas realizadas en el segundo cuarto del s. XVI, se descubren unos rasgos estilísticos comunes. La Piedad conservada en Oviedo no es uno de los temas más habituales entre los de este grupo de pinturas, pero su estilo responde bien a esos rasgos generales atribuidos hasta el momento al Maestro de las Medias Figuras Femeninas y su taller, como se analizará a continuación.

Genaille encontraba que en su estilo se apreciaban influencias de varios maestros, como Bernard van Orley y Jan Gossaert. Un estilo que resultaba próximo a los de Pieter Coecke o Joos van Cleve del foco de Amberes y a los de Benson e Isenbrant, de Brujas. Consideró que el Maestro de las Medias Figuras Femeninas tenía su taller en Amberes y centró su actividad en el segundo cuarto del siglo XVI. ${ }^{3}$ No obstante, este es un punto en que hubo discusión, pues si bien es bastante aceptada la idea de que trabajó en Amberes, Friedländer, por ejemplo, señalaba que se localizaba en Brujas y que quizás posteriormente se trasladase a Amberes, donde su producción tendría mucho sentido y salida; Justi lo había considerado de Brujas y seguidor de Gerard David; ${ }^{4}$ Koch propuso

3 GENAILLE, Robert, 1985, pp. 137-176.

4 BENESCH, Otto, 1943, p. 50. 
que se había formado en Amberes en el taller de Patinir en los años 20. ${ }^{5}$ En todo caso, lo que es evidente es su estilo ecléctico, capaz de aglutinar diferentes influencias no sólo de diversos maestros, sino también de distintos focos. Tampoco es extraño: cada día resulta más claro que existió relación entre los pintores de Amberes, de Brujas y de otras ciudades.

Si bien la pintura conservada en Oviedo muestra las figuras principales de cuerpo entero y una temática religiosa que la alejan de las pinturas más conocidas de este grupo que representan a jóvenes damas de medio cuerpo en actividades como la lectura, la escritura o la interpretación musical, comparte con ellas el gusto por la belleza idealizada y la elegancia, como se puede apreciar, por ejemplo, en los gestos delicados de la Virgen o en el bello rostro de las figuras, dulce y armonioso. ${ }^{6}$

Es habitual en la obra atribuida a este maestro la dimensión reducida de sus pinturas, como sucede en el ejemplo ovetense. Friedländer, en este sentido, argumentaba que era el formato adecuado para el estilo de su obra, alejada del dramatismo y lo heroico y centrada especialmente en los temas amables, delicados. ${ }^{7}$ Incluso una pintura como la Piedad, con la carga dramática y emocional que implica, es tratada de manera amable, eludiendo lo cruel del tema.

En efecto, como se ha señalado, la tabla de Oviedo no se corresponde con la temática habitual de las obras atribuidas al Maestro de las Medias Figuras Femeninas. No obstante, Hernández Perera señalaba que la clientela española también solicitaba de aquel pinturas de la Pasión, además de las más habituales escenas de Infancia y Virgen con Niño. En ese sentido ponía como ejemplo La Lamentación desaparecida de Úbeda o la pintura de Llanto sobre Cristo del Museo de Sevilla. Sobre este tipo de obras decía que demostraban "la escasa vibración dramática de que era capaz el Maestro de las Medias Figuras". ${ }^{8}$

En cuanto a las delicadas figuras, en especial las femeninas, se observa que dispone las cabezas con un marcado perfil oval, con la mirada baja, refinadas cejas, nariz recta y la melena con raya en medio; en la pintura de Oviedo se aprecia especialmente en las figuras masculinas, pues la Virgen y otras mujeres llevan oculto su cabello bajo la toca. El rostro de la Virgen de la Piedad parece muy próximo al de la pintura del Descanso en la Huida a Egipto de la National Gallery, aunque con un menor contraste entre zonas de sombra y de luz. También se podría comparar con el de la Virgen de la Adoración de los Reyes Magos del Museo del Prado, o con el de la Virgen de la Leche en el Museo Lázaro Galdiano.

Por su parte, los tipos masculinos que aparecen en el Santo Entierro de la pintura de Oviedo están tratados de manera sucinta por las dimensiones de la escena, aunque recuerdan a algunas figuras masculinas que aparecen, por ejemplo, en la escena del Nacimiento del Museo Lázaro Galdiano.

Otro elemento en que se aprecian similitudes con otras obras del Maestro de las Medias Figuras Femeninas es el paisaje. El que se representa en la tabla de la Piedad puede compararse por su profundidad, su delicadeza en la ejecución, y el aspecto de la ciudad de Jerusalén. Benesch los describe como "ricos panoramas de meandros, bosques, colinas rocosas y castillos con torres", y los compara con los de Patinir y con los diseños del Ilamado Álbum Errera. ${ }^{9}$

El colorido de las pinturas atribuidas al maestro es brillante, incluso en una escena como la de Oviedo. En ese sentido, se puede observar el rosa intenso del manto de Cristo en la Resurrección y de algunas figuras del Santo Entierro; en las mismas escenas se aprecian los toques rojos en los ropajes de San Juan y de algunos de los guardias del sepulcro; destaca el dorado luminoso del espacio angélico. Todo ello contrasta con el tono terroso predominante del primer plano de esta tabla y de algunos ropajes oscuros, como el que lleva la Virgen.

Tras este análisis comparativo de la Piedad de Oviedo con otras pinturas atribuidas al Maestro

\footnotetext{
${ }^{5}$ KONOWITZ, Ellen, 1999, pp. 1-12, esp. pp. 4 y 6. BERMEJO, Elisa, 2001, pp. 217-238, esp. p. 233.

${ }^{6}$ BENESCH, Otto, 1943, pp. 269-282. Otros ejemplos de la Pasión: MARTENS, Didier, 1990, pp. 237-270.

7 FRIEDLÄNDER, Max J., 1975, pp. 18-21, esp. p. 20.

8 HERNÁNDEZ PERERA, Jesús, 1962, pp. 2-11, esp. p. 8. Sobre otras obras de este maestro en España véase también DíAZ PADRÓN, Matías, 1980, pp. 169-184; 1982, pp. 273-286; DÍAZ PADRÓN, Matías y PADRÓN MÉRIDA, Aida, 1984, pp. 337-356, esp. pp. 346-347; DIÉGUEZ RODRÍGUEZ, Ana, 2005, pp. 343-348.

9 BENESCH, Otto, 1943, pp. 269-282 y 50. Hay una pintura de este Maestro, muy interesante por el tema del paisaje, que es Descanso en la Huida a Egipto, conservada en la National Gallery de Londres (NG720), uno de los edificios, el castillo, se ha comprobado que tiene una estrecha relación con un dibujo conservado en la Albertina de Viena (iv. $7879 \mathrm{v}$ ), dibujo que se relaciona estilísticamente con los del Álbum Errera. Es el mismo castillo. Evidentemente la tabla de Oviedo no presenta una vinculación tan evidente, pero el modo de tratar la ciudad tiene un aire muy familiar. CAMPBELL, Lorne, 2014, p. 518.
} 
de las Medias Figuras Femeninas, no nos parece inadecuado señalar ciertas similitudes entre ellas que pudieran confirmar la atribución primeramente sugerida de la obra.

\section{Una pintura basada en modelos de éxito}

La Piedad del Museo de Bellas Artes de Asturias parece responder a una labor de taller en un contexto de producción "masiva" para satisfacer la demanda de un amplio mercado. Los territorios hispanos fueron grandes consumidores de este tipo de pinturas flamencas, en especial religiosas, durante el siglo XVI. El taller del Maestro de las Medias Figuras estaba bien representado en España gracias a esa importante demanda. Esa producción "masiva", en cualquier taller, lleva a que se llegue a repetir modelos y figuras, no sólo del propio taller sino, a veces, siguiendo modelos de otros. Ello no implica una merma en la calidad estilística, ni en su ejecución, aunque sí en su originalidad. Es lo que ocurre con esta pintura y lo que permite que podamos compararla con otras pinturas del siglo XVI y no necesariamente del mismo taller. Algunas son contemporáneas a la tabla de Oviedo, otras posteriores y también las hay anteriores. De hecho, éstas resultan de especial interés porque han podido servir de modelos a la obra analizada y nos permiten indagar en los orígenes y evolución de los mismos.

Se puede iniciar esa búsqueda de paralelismos con La Piedad con ángeles portadores de las Arma Christi (ant. Col. privada, Madrid).$^{10}$ Ésta carece de las escenas laterales del Santo Entierro y la Resurrección. Hay variaciones en los rostros de las figuras, mostrando, sin duda, una mayor delicadeza los de Oviedo. En la pintura madrileña, el tipo del rostro de la Virgen se distancia del de la de Oviedo, pero lo podríamos poner en comparación con el de la Virgen del Tríptico del Calvario de la GaIleria Sabauda de Turín, ${ }^{11}$ también obra adscrita al Maestro de las Medias Figuras. Resulta llamativa la parte de los ángeles con las Arma Christi ya que es muy similar a la de Oviedo, e incluso sigue el mismo orden en la disposición de los instrumentos de la Pasión. La barrera de nubes que les separa del paisaje es densa también, pero parece que se hubiese querido hacer menos marcada. Hay una mayor presencia de lo sangriento en la versión de Madrid, lo que se ve especialmente bien en la cabeza de Cristo, donde se evidencian las marcas de la corona de espinas, y en la sangre que corre por su costado. La anatomía de Cristo está menos marcada que en la tabla de Oviedo. Los plegados son también análogos: se repiten los pliegues no sólo en la indumentaria de los ángeles, sino también en la de las figuras de la Piedad.

Observamos que en el modelo empleado para ambas pinturas se pueden encontrar unos rasgos comunes, definitorios, que se reiteran en otras obras de las que se hablará a continuación: el detalle del velo de la Virgen, cómo lo sostiene, la mano por detrás del cuello de Cristo, la esquina del perizonium de Cristo sobre el manto de la Virgen formando una especie de triple pliegue, el final apuntado del sudario de Cristo -menos visible en la versión madrileña-, el pliegue lateral alargado del mismo, el dibujo del borde del manto de la Virgen bajo la mano de Cristo; además, podríamos fijarnos en otros detalles menores del plegado. En general, y a pesar de esas similitudes propias de una producción para el mercado, cabe considerar el ejemplar de Oviedo de una mayor calidad estilística que la versión madrileña.

El modelo lo emplea otro destacado artista contemporáneo, Ambrosius Benson, del foco de Brujas. Una de las obras que se le atribuye y que presenta mayor similitud con la tabla de Oviedo es la Piedad de York (1530-1535): aparecen las figuras de Cristo y la Virgen con las mismas posiciones, gestos y detalles en el plegado. ${ }^{12}$ Se diferencia en que en la tabla de York tras la Virgen aparece el poste vertical de la cruz, mientras que en la tabla de Oviedo se ha optado por representar la cruz en un lugar destacado, pero sostenida por un ángel y en un espacio diferenciado.

Esta misma composición de la Piedad la encontramos en otras pinturas de Benson pero formando parte de un grupo más amplio, con más figuras. En la más destacada de todas ellas, la Piedad del Metropolitan Museum de Nueva

\footnotetext{
10 KIK-IRPA, Centro de Primitivos Flamencos, Fototeca, cajón XVle Siècle et Etranger II, Anonymes Espagne (G-V) (21 MAS 14611). En el reverso de la fotografía se señala que se tomó cuando se encontraba en la colección de $D$. José Lázaro Galdiano de Madrid, pero no pasó al Museo. Estuvo atribuida a Adriaen Isenbrandt. Agradezco al Museo Lázaro Galdiano la información facilitada.

11 FRIEDLÄNDER, Max J., 1975, fig. 49.

12 York City Art Gallery, inv. $n^{\circ}$ 832, procedente de la col. de F. D. Lycett Green (1955), Óleo sobre tabla, 37.3 x $29.2 \mathrm{~cm}$. https://rkd.nl/explore/images/62624 (consultado 22/03/2015).
} 
York (h. 1520-1525), ${ }^{13}$ se ha incluido la figura de María Magdalena a los pies de Cristo, tomando una de sus manos, lo que nos puede recordar a algunas composiciones inspiradas en el Llanto sobre Cristo de Quentin Metsys (1507-1508). También es muy interesante la presencia de la figura de San Juan tras la espalda de Cristo, acariciando su frente y posiblemente ayudando a la Virgen a sostenerle: es un gesto más verosímil que el de la Virgen sola sosteniendo a Cristo en la Piedad de Oviedo. La disposición de la corona y los tres clavos en el primer plano se sigue de manera más cercana en la versión madrileña. La presencia de la cruz en el eje de la composición nos recuerda a la pintura de York y se convierte en un elemento fundamental del conjunto. Por lo demás, las figuras de la Virgen y Cristo suponen el mismo modelo que vemos en Oviedo. Este grupo de la Piedad se encuentra también en el centro del políptico de las antiguas colecciones Wrawa de Viena y Chillingworth de Nüremberg, donde se alcanza una mayor complejidad al añadir al grupo las figuras de Nicodemo, José de Arimatea y una santa mujer. ${ }^{14}$ En este caso, la Magdalena ya no sostiene la mano de Cristo sino que unge los pies de Cristo. ${ }^{15}$ En la denominada Pietà Chevallier (ca. 1525-1530) volvemos a encontrarla, su composición es muy similar a la de la National Gallery, pero invertida. Otra mano añadió las figuras de José de Arimatea y Nicodemo: su estilo no tiene nada en común con las otras figuras y de hecho, Marlier señala que parecen obra de un imitador de Pieter Coecke. ${ }^{16}$

Otro artista contemporáneo es el pintor de Brujas Adriaen Isenbrant, discípulo de Gerard David. Él también siguió modelos de su maestro y comparte composiciones con Benson. A Isenbrant se le atribuye una Piedad de especial interés para el estudio de la pintura del museo astu- riano. ${ }^{17}$ La calidad estilística de esa pintura es menor que la habitual en Isenbrant. Encontramos en la parte inferior a la Piedad y en la superior a los ángeles con las Arma Christi, lo mismo que en la pintura de Oviedo y la de Madrid. El rostro de la Virgen de la tabla de Ámsterdam está más próximo a la versión de Madrid; en cambio, las alas de los ángeles lo están a la de Oviedo, son más ornamentales, casi recuerdan las formas de las mariposas. Los plegados, la disposición de las figuras, su distribución, incluso los pequeños detalles, parecen derivar en las tres pinturas del mismo modelo. La de Oviedo está enriquecida por dos escenas más.

Un modelo tan elaborado como el de la Piedad que se analiza, ¿de dónde surge? Parece evidente que la coincidencia en la obra de, al menos, dos talleres indica un modelo previo y común de la Piedad. En el caso de Benson e Isenbrant contaban con la referencia fundamental del pintor Gerard David, en cuyo taller de Brujas trabajaron hasta que lograron tener el suyo propio. En efecto, si repasamos la producción de David, encontramos rápidamente algunas pinturas que pudieron ser la inspiración de ambos. Entre ellas podemos citar La Lamentación de la National Gallery de Londres (1515-1523), en que encontramos también a las tres Marías, y en que destacamos cómo la Virgen sujeta a Cristo por la nuca, el detalle que toman Benson y quizás Isenbrant, mientras que su otra mano, en lugar de sujetar la toca como en los ejemplos mencionados anteriormente, la pasa sobre el pecho de su Hijo, abrazándolo. Más interesante aún y también de David, es La lamentación del Museo de Filadelfia (h. 1515-1520) con ese gesto de abrazo. Similar a ésta es La lamentación de la Iglesia de San Gil de Burgos (ca. 1500). ${ }^{18}$ También La Piedad de la Col. Particular de Oskar Reinhart (ca. 1495-1500), es obra atribuida

\footnotetext{
13 Metropolitan Museum of Art, The Jack and Belle Linsky Collection, Nueva York, 1982, inv. $n^{\circ}$ 1982.60.23, óleo sobre tabla trasladado a lienzo, 91.4 x $56.2 \mathrm{~cm}$., Esta pintura pasó por la col. Sedelmeyer, la Schwartz, luego en venta en Christie's 26-VI1959, la Col. Linsky hasta llegar al Metropolitan Museum. BAUMANN, Guy y LIETDKE, Walter A., 1992, p. 316. https://rkd.nl/ explore/images/62292 (consultado 21/03/2015).

14 Venta en Bonhams (3-XII-2008).

15 Tabla central, óleo sobre tabla, $81 \times 56.5 \mathrm{~cm}$. Marlier señala sobre esta pintura que Cristo y la Magdalena han sido tomados casi literalmente de la Lamentación de Gerard David en la National Gallery, MARLIER, Georges, 1957, p. 91. https://rkd.nl/explore/images/198342 (consultado 10/04/2017).

16 Piedad Chevallier, óleo sobre tabla, 59 x $34.5 \mathrm{~cm}$. Estuvo en la colección Sedelmeyer de París en 1907. MARLIER, Georges, 1957, p. 92, FRIEDLÄNDER, Max. J., 1972, XI, p. 254, https://rkd.nl/explore/images/62296 (consultado 22/03/2015).

17 Apareció en el mercado de arte, en Sothebys, Amsterdam, 2000, 05-08, lote $\mathrm{n}^{\circ} 211$, óleo sobre tabla, 19.1 x $17.3 \mathrm{~cm}$. Anteriormente a la subasta se desconoce su origen. https://rkd.nl/explore/images/108474 (consultado 22/03/2015).

18 FRIEDLÄNDER, Max J., 1972, VIb, fig. 163b. Óleo sobre tabla, 91 x $79.7 \mathrm{~cm}$. Ainsworth señala que el grupo de Lamentaciones (Chicago, y sobre todo Filadelfia, San Gil Brugos y Winthertur) indica una reutilización de modelos como práctica bien desarrollada ya en el taller de David. AINSWORTH, Maryan W., 1998, p. 140, fig. 142.
} 
a Gerard David y no a su círculo. ${ }^{19}$ Aparecen sólo la Virgen y Cristo, la mano tras la nuca, y el brazo extendido abrazándolo; la cruz está en segundo plano pero muy presente. Se aprecia el característico pico del manto de la Virgen. No es difícil suponer que Benson pudo haberse inspirado en esta composición o en alguna similar de David.

En esa línea hay que mencionar una Lamentación atribuida a un seguidor anónimo de David, del Museo Kröller-Müller de Otterlo (primer cuarto s. $\mathrm{XVI}$ ), en que, como en la Pietá de Benson en York ya mencionada, aparecen sólo la Virgen y Jesús. ${ }^{20}$ Durante un tiempo se pensó que era obra del propio David, pero esta atribución se ha retirado. En ella vemos cómo la Virgen sostiene a Cristo con el sudario tras el cuello y lo abraza con su brazo extendido. En primer plano aparecen la corona de espinas, los clavos y las tenazas. Como en la composición de Filadelfia, la figura de Cristo ya no presenta esa frontalidad de la tabla de la National Gallery, sino que se dispone en diagonal. A su vez, el modelo del que parte Gerard David pueden ser las composiciones que desarrolla Rogier van der Weyden en sus pinturas de la Lamentación, como la del Museo del Prado o la del Museo de Bellas Artes de Bruselas.

Por otro lado, la presencia de ángeles portadores de las Arma Christi es habitual en la pintura flamenca desde el siglo XV aunque, como se ha podido ver no en la disposición de la tabla de Oviedo, que también se repite en Madrid y en la tabla atribuida a Isenbrant. Son múltiples los ejemplos que podríamos señalar en pintura, en escultura u otras manifestaciones artísticas en que aparecen los ángeles suspendidos en el aire, con largas túnicas cuyos bajos dibujan artísticos plegados. Además tuvieron un gran eco en Europa, como se puede apreciar, por ejemplo, en escenas hispanas de la Asunción de la Virgen, ya sean pictóricas o escultóricas, de fines del s. XV o de las primeras décadas del s. XVI: la huella de estos plegados es enorme. Los grabados fueron también un buen modo de difusión de este tipo de modelos.
En cuanto a las escenas del fondo de la tabla de Oviedo, la del Santo Entierro presenta una composición que se encuentra también con ligeras variaciones, en la pintura flamenca de la época. Y la Resurrección, por su parte, es un buen ejemplo del uso de grabados como modelos en los talleres flamencos del siglo XVI. En este caso, sigue el de la Resurrección realizada por Durero en 1512, dentro de la serie de la Pasión Grabada (15071512). El pintor lo hace con gran fidelidad: los plegados del manto de Cristo son exactamente iguales; los detalles de la indumentaria de los soldados, hasta el extraño gorro con escamas del soldado que duerme sobre el sepulcro y los nervios de las corazas; las armas; el pequeño elemento en forma de rombo que une ambas partes del sepulcro. Este grabado fue muy popular en los Países Bajos y utilizado por diferentes talleres. Se puede apreciar su huella en el Tríptico de la Pasión en el Museo Diocesano de Zaragoza (ca. 1515), obra del Maestro de Frankfurt, autor destacado del foco de Amberes, ${ }^{21}$ también en el Tríptico de la Lamentación, Col. De Heuve, Bruselas (segundo cuarto del s. XVI), atribuido con dudas al Maestro de la Santa Sangre, del foco de Brujas, y con algunas variaciones fruto de la adaptación del grabado al espacio estrecho del ala de un tríptico; o en el Tríptico de la Pasión de Cristo de Hampton Court, atribuido al Maestro de 1518, del foco de Amberes, aunque tomado de una manera más libre respecto al grabado de Durero. ${ }^{22}$

\section{Conclusiones}

El estudio sobre La Piedad del Museo de Bellas Artes de Asturias, parece confirmar la atribución que se hace de esta pintura al entorno del Maestro de las Medias Figuras Femeninas, uno de los más activos en la producción para el mercado internacional. En concreto, nos parece notable la similitud de muchos detalles de la obra con los que muestran otras de ese mismo autor. Su estilo delicado y amable, con influencia italiana, se combina perfectamente en sus pinturas religiosas con la tradición flamenca y sus composiciones, muy valo-

\footnotetext{
${ }^{19}$ Col. Oskar Reinhart, Winterthur, óleo sobre tabla $80 \times 50 \mathrm{~cm}$. Esta pintura, al parecer, en 1924 se encontraba en Madrid en mercado de arte. FRIEDLÄNDER, Max, J., 1972, vol. VI b, fig. 163a, considerada como réplica de Gerard David, y AINSWORTH, Maryan W., 1998, p. 319; https://rkd.nl/explore/images/49484 (consultado el 22/03/2015).

${ }^{20}$ Museo Kröller-Müller, Otterlo (Ede), Inv. Cat. $n^{\circ} 90$, óleo sobre tabla, 33.8 x $34.8 \mathrm{~cm}$. Estuvo en las colecciones Sedelmeyer de París, von Kaufmann de Berlín, entre otras. FRIEDLÄNDER, Max J., 1972, VI b, fig. 197, atribuida en aquel momento a David, https://rkd.nl/explore/images/27719 (consultado 22/03/2015).

${ }^{21}$ GODDARD, Stephen H., 1983, fig. 191, cat. $n^{\circ}$ 102. Todos los medallones que figuran en esta obra están tomados de los grabados de Durero.

22 CAMPBELL, Lorne, 1985, cat. n 44, fig. 54
} 
radas en Europa. Posiblemente ésta es la razón de su éxito y de la presencia de un número notable de sus obras en España.

Asimismo, podemos concluir que es un buen ejemplo de obra devocional del siglo XVI, tanto por sus dimensiones como por su iconografía. También supone un ejemplo del modo de trabajo de los talleres flamencos que, para satisfacer una amplia demanda local e internacional, recurrieron al uso de modelos pictóricos y grabados de éxito.

En efecto, como queda demostrado, el tema protagonista de la tabla, la Piedad, responde a uno de esos modelos de éxito que se repiten en los talleres de Amberes y Brujas. Buscando sus orígenes es posible retroceder desde el Maestro de las Medias Figuras, Ambrosius Benson y otros contemporáneos a una generación anterior, la de Gerard David que, a su vez, se puede enlazar con uno de los grandes pintores del s. XV, Rogier van der Weyden, cuyas composiciones fueron abundantemente copiadas y reinterpretadas por los pintores flamencos posteriores.

\section{Bibliografía}

AINSWORTH, Maryan W. Gerard David. Purity of Vision in an Age of Transition. New York: The Metropolitan Museum of Art, 1998.

BAUMANN, Guy y LIETDKE, Walter A. Flemish Paintings in America: A Survey of Early Netherlandish Paintings in the Public Collections of North America. Amberes: Fonds Mercator, 1992.

BENESCH, Otto. "The name of the Master of the Halflenghts". Gazette des Beaux Arts, 1943, XXIII, París, pp. 269-282.

BERMEJO, Elisa. "Importantes pinturas de los Países Bajos en colecciones privadas españolas". Archivo Español de Arte, 2001, 295, pp. 217-238.
CAMPBELL, Lorne. The Early Flemish Pictures in the CoIlection of Her Majesty the Queen. Cambridge: Cambridge University Press, 1985.

CAMPBELL, Lorne. The Sixteenth Century Netherlandish Paintings with French Paintings before 1600. Londres: National Gallery \& Yale University Press, 2 vols., 2014.

DÍAZ PADRÓN, Matías. "Nuevas pinturas del Maestro de las Medias Figuras". Archivo Español de Arte, 1980, 210, pp. 169-184.

DÍAZ PADRÓN, Matías. "Pintores flamencos del XVI: Tablas del Maestro de las Medias Figuras identificadas en España, Caracas y Santiago de Chile y un Juicio Final de Michel Coxcie". Archivo Español de Arte, 1982, 219, pp. 273-286.

DíAZ PADRÓN, Matías y PADRÓN MÉRIDA, Aida. "Miscelánea de pintura flamenca del siglo XVI". Archivo Español de Arte, 1984, 228, pp. 337-356.

DIÉGUEZ RODRÍGUEZ, Ana. "Una pequeña Virgen de la Leche del Maestro de las Medias Figuras en el Convento de Carmelitas Descalzas de San José de Ávila". Boletín del Seminario de Arte y Arqueología, 2005, LXXI, pp. 343-348.

FRIEDLÄNDER, Max J. "The Master of the Female HalfLengths". En Early Netherlandish Painting, vol XII. Bruselas: La Connaissance, 1972, pp. 18-21.

GENAILLE, Robert. "À propos du Maître des demi-figures féminines". Koninklijk Museum voor Schone Kunsten-Antwerpen Jaarboek, 1985, pp. 137-176.

GODDARD, Stephen H. The Master of Frankfurt and his Shop. 2 vols., Thesis Ph D, University of lowa, 1983.

HERNÁNDEZ PERERA, Jesús. "Museo español del Maestro de las Medias Figuras". Goya, 1962, 49, pp. 2-11.

KONOWITZ, Ellen. "The Master of the Female HalfLengths Group, Eclecticism, and Novelty". Oud-HoIland, 1999, XI, 1/2, pp. 1-12.

MARLIER, Georges. Ambrosius Benson et la Peinture à Bruges au Temps de Charles V. Damme: Editions du Musée Van Maerlant, 1957.

MARTENS, Didier. "Une Crucifixion flamande et sa descendance au XVle siècle. Lecture d'une séquence de copies". Konninklijk Museum voor Schone Kunsten 1990, pp. 237-270. 
